\title{
Efeitos da Restrição Alimentar Protéica ou Energética sobre o Crescimento de Frangos de Corte Criados em Diferentes Temperaturas Ambiente
}

\author{
Elizabete Regina Leone1, Francisco Ernesto Moreno Bernal2 ${ }^{2}$, Renato Luís Furlan³, Euclides \\ Braga Malheiros ${ }^{4}$, Marcos Macari ${ }^{5}$
}

\begin{abstract}
RESUMO - O presente experimento foi conduzido com o objetivo de avaliar o efeito da restrição protéica ou energética, entre o 8 o e o 14으 dia de idade, sobre o crescimento e a composição da carcaça de frangos de corte criados em diferentes temperaturas ambientes. Foram utilizados 900 pintos de um dia, machos, da linhagem Ross, os quais foram alojados em três diferentes câmaras climatizadas nas temperaturas de 18,25 ou $33^{\circ} \mathrm{C}$, do $1^{\circ}$ ao $42^{\circ}$ dia de idade. Para cada temperatura, o delineamento experimental utilizado foi o inteiramente casualizado, em esquema de parcelas subdivididas, em que as parcelas corresponderam ao programa alimentar (controle - $2850 \mathrm{kcal}$ EM/kg e $20 \%$ de proteína bruta do $1 \underline{\mathrm{O}}$ ao $21^{\mathrm{O}}$ dia de idade e $3040 \mathrm{kcal} \mathrm{EM} / \mathrm{kg}$ e $17 \%$ de PB do $22 \underline{\mathrm{O}}$ ao $42^{\mathrm{O}}$ dia; restrição energética - $2565 \mathrm{kcal}$ EM/kg e $20 \%$ de PB e restrição protéica - $2850 \mathrm{kcal} \mathrm{EM} / \mathrm{kg}$ e $15 \%$ de PB entre o $8 \underline{0}$ e o 14 o dia de idade) e as subparcelas, à idade das aves. Entre o $1^{\mathrm{o}}$ e o $7 \underline{\mathrm{o}}$ dia de idade e após o período de restrição as aves receberam a mesma dieta do que os animais controles. Foram avaliados o peso vivo e a composição da carcaça das aves. Os resultados mostraram que, de forma independente da temperatura de criação, as restrições alimentares (energética ou protéica) não afetaram o peso vivo e a composição da carcaça aos 42 dias de idade, evidenciando que o frango em temperaturas ambientes diversas mantém a capacidade de ganho compensatório.
\end{abstract}

Palavras-chave: frango de corte, restrição alimentar qualitativa, temperatura ambiente

\section{Effect of Protein or Energy Restriction on Broilers Growth Reared at Different Environmental Temperatures}

\begin{abstract}
The present experiment was conducted to evaluate the effect of protein or energy restriction from $8^{\text {th }}$ to $14^{\text {th }}$ days of age, on growth and carcass composition of broiler chickens raised at different environmental temperatures. It was used 900 day-old, male chickens from Ross strain, reared in three environmentally controlled rooms where ambient temperature were maintained at 18 , 25 and $33^{\circ} \mathrm{C}$ up to 42 days of age. For each temperature, a split-plot design was used with feed program as the main plot (control - 2850 $\mathrm{kcal} \mathrm{ME} / \mathrm{kg}$ and $20 \%$ of crude protein from 1 to 21 days and $3040 \mathrm{kcal} \mathrm{ME} / \mathrm{kg}$ and $17 \%$ of crude protein from 22 to 42 days; energy restriction - $2565 \mathrm{kcal} \mathrm{ME} / \mathrm{kg}$ and $20 \%$ of crude protein and protein restriction $-2850 \mathrm{kcal} \mathrm{ME} / \mathrm{kg}$ and $15 \%$ of crude protein from $8^{\text {th }}$ to $14^{\text {th }}$ days of age) and age as the sub-plot. From 1 to 7 days of age and after restriction period, the chicks were fed with the control diet. The body weight and carcass composition were analyzed. The results showed that, irrespective of ambient temperature, the qualitative energy or protein restriction did not affect the body weight and carcass composition at 42 days of age, indicating that broilers kept a compensatory gain ability in different ambient temperatures.
\end{abstract}

Key Words: broiler, environmental temperature, qualitative feed restriction

\section{Introdução}

A seleção genética e as mudanças nutricionais disponíveis nas últimas décadas têm contribuído na obtenção de maiores ganhos de peso e melhores conversões alimentares, reduzindo o tempo de abate das aves, aumentando, contudo, a incidência de problemas de desenvolvimento esquelético e metabólicos (síndrome da hipertensão pulmonar). Programas envolvendo restrições alimentares vêm sendo gradativamente aplicados no intuito de reduzir os problemas metabólicos, bem como baratear os custos de produção. Nesse sentido, segundo ROBINSON et al. (1992), a idade ótima para se efetuar a restrição alimentar seria na segunda semana de vida, com benefícios evidentes em relação à redução do número de aves com problemas de desenvolvimento ósseo e metabólicos. Entretanto, devem-se observar alguns

\footnotetext{
1 Estudante do curso de Zootecnia da FCAV/UNESP.

2 Pós-Graduando de Doutorado da FCAV/UNESP.

3 Professor Assistente Doutor - Depto de Morfologia e Fisiologia Animal. E.mail: rlfurlan@fcav.unesp.br

4 Professor Titular - Departamento de Ciências Exatas da FCAV/UNESP. E.mail: euclides@fcav.unesp.br

5 Professor Titular do Depto de Morfologia e Fisiologia Animal. Rod. Paulo Donato Castellane, CEP: $14.870-000$ Jaboticabal - SP - Brasil. E.mail macari@fcav.unesp.br
} 
fatores que influenciam a correta utilização da restrição alimentar, como o sexo, a linhagem, duração da restrição, idade e quantidade de alimento ingerido na realimentação.

Até recentemente acreditava-se que o frango, com seu relativo curto ciclo de vida, não teria tempo suficiente para ter compensação no crescimento após um período de restrição alimentar (AUCKLAND e MORRIS, 1971). No entanto, PLAVNIK e HURWITZ (1985) mostraram a possibilidade de ganho compensatório em frangos de corte submetidos a curtos períodos de restrição alimentar à idade precoce. Estudos de ZUBAIR e LEESON (1994) também sugeriram ganho compensatório em aves após um período de restrição alimentar. GONZALES (1992) concluiu que a restrição alimentar $(50 \%)$, em frangos de corte, deve ser seguida de pelo menos três semanas de realimentação, período necessário para que a aves apresentem ganho compensatório e, conseqüentemente, peso final semelhante ao dos frangos com consumo à vontade. Outros autores, no entanto, não encontraram os mesmos resultados, ficando os animais com déficit no peso corporal após a restrição alimentar e, sugeriram que o ganho compensatório não existe (MOLLINSON et al., 1984; CABEL e WALDROUP, 1990; YU et al., 1990).

JONES e FARREL (1992) relataram que o sucesso da restrição alimentar na recuperação do peso corporal e no decréscimo da gordura da carcaça estaria associado a um balanço negativo de energia e positivo de nitrogênio durante a fase de restrição; entretanto, alertaram para o fato desta restrição não ser efetuada por longos períodos. MORAN JR. (1992) concluiu serem necessárias oito semanas de realimentação para que as aves consigam recuperar a perda de peso ocasionada pela restrição alimentar precoce. SARTORI et al. (1997), realizando restrição alimentar tardia (duas semanas antes do abate), observaram menor ganho de peso nas aves restritas, quando comparadas às aves alimentadas ad libitum à época do abate, sugerindo que o período de realimentação foi muito curto para adaptação das aves ao consumo de alimento e conseqüente ganho compensatório.

Até recentemente a maioria dos estudos sobre ganho compensatório em frangos de corte enfocava basicamente se as aves restritas teriam peso similar às aves alimentadas ad libitum a época do abate. No entanto, é necessário maior conhecimento do impacto de um programa de restrição sobre o organismo (ganho de proteína, como tecido muscular ou gordura, como tecido adiposo) após a realimentação em fran- gos previamente restritos. Nesse sentido, este trabalho foi conduzido com o objetivo de avaliar o efeito da restrição protéica ou energética, entre o $8^{\circ}$ e $14^{\circ}$ dia de idade, sobre o crescimento e a composição da carcaça de frangos de corte, quando criados em diferentes temperaturas ambientes.

\section{Material e Métodos}

Foram utilizados 900 pintos de corte machos, da linhagem comercial Ross, alojados em três câmaras climatizadas nas temperaturas constantes de $18,25 \mathrm{e}$ $33^{\circ} \mathrm{C}$, do $1^{\mathrm{O}}$ ao $42^{\circ} \mathrm{o}$ dia de idade. Cada câmara climática possuía as dimensões de $9 \mathrm{~m}$ de largura, 6,5 $\mathrm{m}$ de comprimento e pé direito de $3 \mathrm{~m}$, possuindo 16 boxes (2,50 m de comprimento $\mathrm{x} 1,10 \mathrm{~m}$ de largura) separados entre si por tela de arame galvanizado. O piso era de alvenaria e as laterais e o teto eram revestidos com placas de poliuretano injetado. Para a renovação do ar, cada câmara possuía dois ventiladores e dois exaustores. Para se obterem as temperaturas desejadas em cada câmara climática, dispunha-se de aquecedores elétricos e refrigeradores de ar controlados por termostatos.

Nos sete primeiros dias de vida, todas as aves receberam uma ração contendo $2850 \mathrm{kcal}$ de EM/kg de ração e $20 \%$ de proteína bruta. Durante o período de restrição alimentar ( $8^{\circ} \underline{0}$ ao $14^{0}$ dia de vida), as aves foram arraçoadas com um dos três tipos de rações: o grupo controle recebeu uma ração contendo $2850 \mathrm{kcal}$ de EM/kg de ração e $20 \%$ de proteína bruta (relação energia $(E)$ : proteína $(P)=142,50)$ em cada ambiente; um segundo grupo de animais recebeu uma ração contendo $2565 \mathrm{kcal}$ de $\mathrm{EM} / \mathrm{kg}$ de ração e $20 \%$ de proteína bruta $(E: P=128,25)$ em cada ambiente; e um terceiro grupo recebeu uma ração contendo $2850 \mathrm{kcal}$ de $E M / k g$ de ração e $15 \%$ de proteína bruta $(\mathrm{E}: \mathrm{P}=$ 190,00) em cada ambiente. Após o período de restrição, do $15^{\circ}$ o ao $21^{\circ}$ o dia de idade, todos os grupos receberam ração contendo $2850 \mathrm{kcal} \mathrm{de} \mathrm{EM/kg} \mathrm{de}$ ração e $20 \%$ de proteína bruta. Na fase final (22-42 dias de idade), para os três grupos, foi utilizada ração contendo $3040 \mathrm{kcal}$ de EM/kg de ração e $17 \%$ de proteína bruta $(\mathrm{E}: \mathrm{P}=178,82)$. O programa de arraçoamento e as composições das rações utilizadas no experimento são apresentados nas Tabelas 1 e 2 , respectivamente.

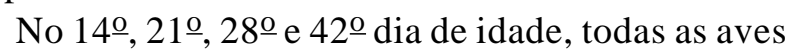
foram pesadas, sendo retirados, ao acaso, oito frangos de cada tratamento para a determinação da composição química da carcaça (proteína bruta, ex- 
1060 Rev. bras. zootec.

Tabela 1 - Programa de alimentação

Table 1 - Feeding program

Programa de alimentação

Feeding program

\begin{tabular}{lcccr}
$\begin{array}{l}\text { Idade (dias) } \\
\text { Age (days) }\end{array}$ & $\begin{array}{c}\text { Nível nutricional } \\
\text { Nutritional level }\end{array}$ & $\begin{array}{c}\text { Controle } \\
\text { Control }\end{array}$ & $\begin{array}{c}\text { Restrição energética } \\
\text { Energy restriction }\end{array}$ & $\begin{array}{c}\text { Restrição protéica } \\
\text { Protein restriction }\end{array}$ \\
\hline $1-7$ & EM(kcalEM) & 2850 & 2850 & 2850 \\
& PB (\%) & 20 & 20 & 20 \\
$8-14$ & EM(kcalEM) & 2850 & 2565 & 2850 \\
& PB (\%) & 20 & 20 & 15 \\
$15-21$ & EM(kcalEM) & 2850 & 2850 & 2850 \\
$22-41$ & PB (\%) & 20 & 20 & 20 \\
& EM(kcalEM) & 3040 & 3040 & 3040 \\
\hline
\end{tabular}

$\mathrm{EM}(M E) ; \mathrm{PB}(C P)$.

Tabela 2 - Composição das rações experimentais

Table 2 - Composition of experimental diets

Rações experimentais

Experimental diets

Ingredientes (\%)

Ingredients

Milho moído

Ração 1

Ração 3

Ration 2

Ration 3

Ração 4

$61,750 \quad 52,607$

66,500

Corn

Farelo de soja

31,946

33,637

20,741

25,750

meal

0,129

0,000

1,193

3,901

Soybean oil

Inerte

1,175

8,756

6,566

3,599

Inert

Núcleo ${ }^{1}$

5,000

5,000

5,000

5,000

Vitamin-mineralmix

Total

100,000

100,000

100,000

100,000

Composição calculada

Calculated composition

Proteína bruta (\%)

20

20

15

17

Crude protein

Energia metabolizável (kcal/kg) 2850

Metabolizable energy

Metionina

0,419

2565

2850

3040

Methionine

Met + Cist (\%)

0,651

0,415

0,352

0,378

$\mathrm{Met}+\mathrm{Cys}$

Lisina (\%)

1,059

0,642

0,515

0,566

Lysine

Cácio (\%)

1,007

1,086

0,748

0,881

Calcium

P disponível (\%)

0,390

1,012

0,968

0,985

Available $P$

\footnotetext{
1 Núcleo vitamínico e mineral (Vitamin-mineral mix), Níveis/kg (levels/kg): Vit. A 176000 UI, Vit. $D_{3} 4000$ UI, Vit. K 100 mg, Vit. B 36 mg, Vit. B 200 mg, Vit. $\mathrm{B}_{6} 50 \mathrm{mg}$, Vit. $\mathrm{B}_{12} 560 \mathrm{mcg}$, Niacina (Niacin) $700 \mathrm{mg}$, Biotina (Biotin) $3 \mathrm{mg}$, Ácido pantotênico (Pantothenic acid) $500 \mathrm{mg}$, Ácido fólico (Folic acid) 30 mg, Colina (Choline) 20 mg, Fe 1000 mg, Cu 300 mg, Mn 1800 mg, Zn 1200 mg, I 24 mg, Se 3 mg, Ca 176 g, P 68 g, Na 23 g, Cl 36 g, promotor de crescimento (Growth promoter) $2 \mathrm{~g}$, coccidiostático (coccidiostatic) $10 \mathrm{~g}$, e BHT (antioxidant) $1 \mathrm{~g}$.
} 
trato etéreo e cinzas). No preparo das amostras, as carcaças foram moídas inteiras, inclusive com penas, em um moedor industrial de carnes (C.A.F. Picadores de carne - FB- 09/93), homogeneizadas e colocadas para secar em estufas de ventilação forçada a $55^{\circ} \mathrm{C}$ por 72 horas e, posteriormente, trituradas em moinho de faca. As análises laboratoriais para determinação da proteína bruta, extrato etéreo e cinzas foram realizadas de acordo com as técnicas preconizadas pela ASSOCIATION OF OFFICIAL ANALYTICAL CHEMISTRY - AOAC (1975).

Para cada temperatura, o delineamento experimental utilizado foi o inteiramente casualizado, segundo esquema em parcelas subdivididas, em que as parcelas constituíram o programa alimentar (controle, restrição de energia ou restrição de proteína) e as subparcelas, a idade das aves (dias). As análises de variância foram realizadas por meio do procedimento GLM do SAS $\AA^{\circledR}$ (1998). Para verificar a significância entre as médias dos tratamentos, foi utilizado o teste de Tukey a $5 \%$ de probabilidade.

\section{Resultados e Discussão}

Analisando os resultados da Tabela 3, infere-se que, em ambas as temperaturas ambiente de $25 \mathrm{e}$ $33^{\circ} \mathrm{C}$, as restrições protéica ou energética não influenciaram o peso corporal das aves aos 14 dias de idade, no entanto, na temperatura ambiente de $18^{\circ} \mathrm{C}$, os dados evidenciaram que a restrição protéica mostrou-se mais severa $(\mathrm{P}<0,05)$ em reduzir o peso vivo dos frangos, quando comparado com o tratamento controle. Já a restrição energética proporcionou peso semelhante aqueles apresentados pelas aves do grupo controle e com restrição protéica. As proteínas são fundamentais no aspecto nutricional e metabólico para os frangos, pois estão relacionadas aos processos do organismo como a formação dos tecidos estruturais (músculo). Entretanto, o turnover (síntese e degradação) protéica do músculo esquelético pode ser influenciado pelo nível nutricional. Nesse sentido, a redução verificada no peso corporal estaria relacionada com a falta de crescimento da massa muscular (menor síntese protéica), a qual depende diretamente do cumprimento nos requerimentos protéicos para o frango de corte em crescimento, requerimentos estes, provavelmente, prejudicados devido a uma alta relação E:P.

Uma semana após a realimentação (21 dias de idade), não foi encontrada diferença significativa para peso vivo dos frangos de corte restritos em proteína, em relação ao grupo controle, efeito este observado até o final do experimento (42 dias de idade), indicando ganho compensatório para as aves que foram submetidas à restrição alimentar protéica a $18^{\circ} \mathrm{C}$. Resultados semelhantes foram obtidos por GIACHETTO et al. (1998), que observaram ganho compensatório nas semanas subseqüentes à restri-

Tabela 3 - Peso corporal $(\mathrm{g})$ dos frangos de corte. Valores expressos como a média \pm erro-padrão da média Table 3 - Body weight $(\mathrm{g})$ of broiler chickens. Each value represents mean $\pm S E M$

\begin{tabular}{|c|c|c|c|c|c|}
\hline \multirow[t]{2}{*}{$\begin{array}{l}\text { Temperatura } \\
\text { Temperature }\end{array}$} & \multirow[t]{2}{*}{$\begin{array}{c}\text { Tratamento } \\
\text { Treatment }\end{array}$} & \multicolumn{4}{|c|}{$\begin{array}{c}\text { Idade (dias) } \\
\text { Age (days) }\end{array}$} \\
\hline & & 14 & 21 & 28 & 42 \\
\hline \multirow{4}{*}{$18^{\circ} \mathrm{C}$} & $\mathrm{C}^{2}$ & $302 \pm 8,5^{\mathrm{a} 1}$ & $628 \pm 21,5^{a}$ & $979 \pm 38,4^{\mathrm{a}}$ & $1957 \pm 37,9^{a}$ \\
\hline & $\mathrm{RE}^{3}$ & $289 \pm 3,3^{a b}$ & $599 \pm 8,2^{\mathrm{a}}$ & $940 \pm 9,9^{a}$ & $1910 \pm 46,5^{a}$ \\
\hline & $\mathrm{RP}^{4}$ & $264 \pm 6,2^{b}$ & $570 \pm 13,5^{\mathrm{a}}$ & $896 \pm 28,7^{\mathrm{a}}$ & $1844 \pm 37,3^{\mathrm{a}}$ \\
\hline & $\mathrm{CV}(\%)^{5}$ & 15,81 & 11,12 & 14,87 & 14,97 \\
\hline \multirow{3}{*}{$25^{\circ} \mathrm{C}$} & $\mathrm{C}$ & $294 \pm 8,7^{a}$ & $595 \pm 12,3^{a}$ & $939 \pm 36,7^{a}$ & $1917 \pm 32,1^{a}$ \\
\hline & $\mathrm{RE}$ & $295 \pm 12,1^{\mathrm{a}}$ & $611 \pm 18,7^{\mathrm{a}}$ & $965 \pm 32,1^{\mathrm{a}}$ & $1904 \pm 71.5^{\mathrm{a}}$ \\
\hline & $\mathrm{RP}$ & $299 \pm 9,1^{\mathrm{a}}$ & $601 \pm 4,2^{\mathrm{a}}$ & $946 \pm 22,3^{\mathrm{a}}$ & $1909 \pm 33,8^{a}$ \\
\hline \multirow{5}{*}{$33^{\circ} \mathrm{C}$} & $\mathrm{CV}(\%)$ & 15,30 & 14,00 & 12,39 & 14,49 \\
\hline & C & $283 \pm 11,4^{\mathrm{a}}$ & $527 \pm 18,7^{\mathrm{a}}$ & $783 \pm 24,7^{\mathrm{a}}$ & $1419 \pm 79,4^{\mathrm{a}}$ \\
\hline & $\mathrm{RE}$ & $270 \pm 6,9^{\mathrm{a}}$ & $542 \pm 20,2^{\mathrm{a}}$ & $819 \pm 10,9^{a}$ & $1366 \pm 57,8^{a}$ \\
\hline & $\mathrm{RP}$ & $264 \pm 11,2^{\mathrm{a}}$ & $512 \pm 20,9^{a}$ & $766 \pm 23,8^{a}$ & $1395 \pm 53,4^{\mathrm{a}}$ \\
\hline & $\mathrm{CV}(\%)$ & 14,60 & 15,97 & 10,50 & 11,50 \\
\hline \multicolumn{6}{|c|}{$\begin{array}{ll}1 & \text { Dentro de cada temperatura, médias de um } \\
& \text { (Means within a column for each temperature followe } \\
2 & \text { Grupo controle (Control group). } \\
3 & \text { Restrição energética (Energy restriction). } \\
4 & \text { Restrição protéica (Protein restriction). } \\
5 & \text { Coeficiente de variação (Coefficient of variation). }\end{array}$} \\
\hline
\end{tabular}


1062 Rev. bras. zootec.

ção alimentar quantitativa com recuperação no peso das aves restritas-realimentadas. PLAVNIKetal.(1986) descreveram que o ganho compensatório ocorria duas semanas após a realimentação das aves restritas. Porém, CALVERT et al. (1987) reportaram que, após a restrição alimentar, os animais ficaram sujeitos a um déficit no peso corporal. FURLAN(1996), restringindo frangos quantitativamente entre o $200^{\circ}$ e 270 dia de idade, também observou que as aves restritas não atingiram o peso dos animais alimentados ad libitum ao final do período de realimentação (34 dias de idade).

Pelos resultados da Tabela 3, pode-se observar que dentro de cada temperatura ambiente, ao se aplicar a restrição alimentar qualitativa, não foram observadas diferenças significativas $(\mathrm{P}>0,05)$ no peso corporal entre os animais restritos em energia (RE) ou proteína (RP) quando comparados ao grupo controle (C), exceto ao final do período de restrição alimentar (140 dia) à temperatura ambiente de $18^{\circ} \mathrm{C}$. Considerando que o crescimento depende da relação E:P, estes achados sugerem que a redução temporária (uma semana) nesta relação pode influenciar o ganho em peso dos frangos de corte, dependendo da temperatura na qual os animais estão sendo submetidos. Assim, em temperaturas ambientais abaixo da zona de conforto, mudanças da relação E:P parece ser mais efetiva em alterar o ganho de peso do que quando em temperaturas termoneutra ou calor. Por outro lado, os achados mostraram que o aumento da relação E:P é mais efetivo em alterar o ganho em peso no ambiente frio, quando comparado com a redução desta relação. Assim, a disponibilidade de aminoácidos para o crescimento é o fator limitante para o desenvolvimento dos frangos de corte quando da restrição qualitativa. O uso de energia da carcaça, quando efetuada a restrição em energia, pode ser verificado por meio dos resultados apresentados na Tabela 4, que mostra a redução da gordura (extrato etéreo) da carcaça no final do período de restrição alimentar. É interessante salientar que os animais com restrição protéica, em temperaturas termoneutra e fria, mostraram maiores teores, em valor absoluto, de extrato etéreo na carcaça, sugerindo menor utilização deste substrato durante o período de restrição.

A utilização da restrição alimentar justifica-se tanto do ponto de vista da qualidade do produto a ser oferecido ao consumidor; ou seja, carcaça com maior quantidade de massa muscular e menor de gordura, bem como uma forma alternativa de manejo em condições de estresse de calor (para redução da morbidade e mortalidade) e de frio (diminuição da incidência de ascite). Os resultados obtidos neste experimento mostraram que a restrição alimentar imposta (8-14 dias) não reduziu $(\mathrm{P}>0,05) \mathrm{o}$ teor de gordura da carcaça, quando comparadas aos animais do grupo controle no final do período experimental. FONTANA et al. (1993) sugeriram ocorrer alta atividade lipogênica em frangos restritos-realimentados, quando comparados com animais alimentados à vontade. Este fato foi verificado por ROSEBROUGH e McMURTRY (1993), que encontraram aumento na lipogênese em frangos de corte nos três dias após a realimentação. FURLAN (1996) observou que a quantidade total de gordura da carcaça e a gordura abdominal foram reduzidas somente durante o período de restrição alimentar quantitativa, atingindo valores semelhantes aos animais alimentados à vontade após a realimentação. Estes resultados sugerem que, durante o período de realimentação, o frango de corte procura repor a energia utilizada durante o período de restrição alimentar, fazendorápida deposição de triacilglicerol nos adipócitos. No entanto, JONES e FARREL (1992) reportaram decréscimo na gordura da carcaça de frangos de corte, quando da restrição qualitativa, sendo o mesmo associado a um balanço negativo de energia e positivo de nitrogênio.

Os resultados da análise química da carcaça são apresentados na Tabela 4. Foi verificado que após o período de restrição (14을a) houve redução protéica na carcaça, evidenciando maior mobilização de substrato protéico nos animais restritos em proteína, quando comparados com os restritos em energia, independente da temperatura de criação das aves. Contudo, duas semanas após a realimentação, não foram encontradas diferenças significativas entre os tratamentos. Estes achados mostram que a restrição alimentar qualitativa (energética ou protéica), quando realizada durante a fase inicial de desenvolvimento do frango de corte, não é capaz de alterar de forma significativa a quantidade de proteína na carcaça da ave. De acordo com PENZ JR. (1992), é possível minimizar os problemas associados ao calor pelamanipulação dos nutrientes, tal como a diminuição da proteína bruta da ração, sem comprometer os níveis dos aminoácidos limitantes. WALDROUP et al. (1976), utilizando programas de restrições qualitativas, tanto energética quanto protéica, também mostraram a viabilidade do uso da restrição alimentar, sugerindo que este manejo nutricional poderia reduzir o incremento calórico proveniente dos nutrientes, além da possibilidade de formulação de rações de menor custo. A temperatura de criação da ave não foi fator relevante em reduzir ou aumentar o conteúdo protéico da carcaça dos frangos, pois aos 42 dias de idade os resultados não mostraram diferenças significativas entre os tratamentos.

Verifica-se na Tabela 4 que o teor de cinzas da carcaça não foi alterado em função da restrição 


\section{LEONE et al.}

1063

alimentar qualitativa. Os resultados mostraram que, mesmo após o período de restrição, não ocorreu diferença significativa $(\mathrm{P}>0,05)$ no teor de cinzas da carcaça, independente da temperatura de criação dos frangos de corte. Trabalhando com restrição no período final de criação de frangos, SARTORI et al.
(1997 b) verificaram que frangos restritos apresentaram maior teor de cinza na carne do peito e da coxa, quando comparados com aves alimentadas ad libitum. Outros trabalhos têm mostrado que a temperatura ambiente e mesmo a restrição alimentar alteram o crescimento de ossos longos (DALE, 1993;

Tabela 4 - Composição da carcaça dos frangos de corte. Valores expressos como a média \pm erro-padrão da média Table 4 - Carcass composition of broiler chickens. Each value represents mean \pm SEM

\begin{tabular}{|c|c|c|c|c|c|}
\hline \multirow[t]{2}{*}{$\begin{array}{l}\text { Temperatura } \\
\text { Temperature }\end{array}$} & \multirow[t]{2}{*}{$\begin{array}{c}\text { Tratamento } \\
\text { Treatment }\end{array}$} & \multicolumn{4}{|c|}{$\begin{array}{c}\text { Idade (dias) } \\
\text { Age (days) }\end{array}$} \\
\hline & & 14 & 21 & 28 & 42 \\
\hline & & \multicolumn{4}{|c|}{ Extrato etéreo (\%) } \\
\hline & $\mathrm{C}^{2}$ & $30,0 \pm 0,9^{\mathrm{b} 1}$ & $33,5 \pm 1,3^{\mathrm{a}}$ & $35,7 \pm 1,1^{\mathrm{a}}$ & $40,6 \pm 1,4^{\mathrm{a}}$ \\
\hline \multirow[t]{4}{*}{$18^{\circ} \mathrm{C}$} & $\mathrm{RE}^{3}$ & $28,8 \pm 1,7^{b}$ & $31,3 \pm 1,0^{\mathrm{a}}$ & $32,4 \pm 1,2^{\mathrm{a}}$ & $37,1 \pm 1,0^{\mathrm{a}}$ \\
\hline & $\mathrm{RP}^{4}$ & $34,8 \pm 1,0^{\mathrm{a}}$ & $35,3 \pm 2,8^{a}$ & $34,9 \pm 0,6^{\mathrm{a}}$ & $38,0 \pm 1,4^{\mathrm{a}}$ \\
\hline & $\mathrm{CV}(\%)^{5}$ & 11,33 & 15,84 & 8,04 & 9,43 \\
\hline & $\mathrm{C}$ & $32,5 \pm 1,4^{b}$ & $38,1 \pm 2,9^{a}$ & $39,3 \pm 0,6^{\mathrm{a}}$ & $40,7 \pm 1,1^{\mathrm{a}}$ \\
\hline \multirow[t]{4}{*}{$25^{\circ} \mathrm{C}$} & $\mathrm{RE}$ & $31,9 \pm 1,0^{\mathrm{b}}$ & $39,2 \pm 1,1^{\mathrm{a}}$ & $38,1 \pm 1,0^{\mathrm{a}}$ & $42,3 \pm 0,6^{\mathrm{a}}$ \\
\hline & $\mathrm{RP}$ & $39,7 \pm 0,9^{a}$ & $39,6 \pm 1,2^{\mathrm{a}}$ & $40,5 \pm 0,7^{\mathrm{a}}$ & $41,4 \pm 1,1^{\mathrm{a}}$ \\
\hline & $\mathrm{CV}(\%)$ & 8.99 & 13,99 & 6,26 & 6,58 \\
\hline & $\mathrm{C}$ & $34,9 \pm 1,6^{\mathrm{a}}$ & $41,1 \pm 4,0^{\mathrm{a}}$ & $37,5 \pm 0,7^{\mathrm{a}}$ & $41,7 \pm 1,1^{\mathrm{a}}$ \\
\hline \multirow[t]{5}{*}{$33^{\circ} \mathrm{C}$} & $\mathrm{RE}$ & $36,6 \pm 2,6^{a}$ & $35,4 \pm 0,6^{\mathrm{a}}$ & $37,4 \pm 0,7^{\mathrm{a}}$ & $42,4 \pm 1,1^{\mathrm{a}}$ \\
\hline & $\mathrm{RP}$ & $40,6 \pm 0,9^{\mathrm{a}}$ & $37,9 \pm 1,0^{\mathrm{a}}$ & $39,2 \pm 1,3^{\mathrm{a}}$ & $43,7 \pm 1,7^{\mathrm{a}}$ \\
\hline & $\mathrm{CV}(\%)$ & 13,81 & 17,73 & 6,77 & 8,80 \\
\hline & & \multicolumn{4}{|c|}{ Proteína (\%) } \\
\hline & $\mathrm{C}$ & $51,1 \pm 0,8^{\mathrm{a}}$ & $51,2 \pm 0,9^{b}$ & $47,8 \pm 0,6^{\mathrm{a}}$ & $44,1 \pm 1,3^{\mathrm{a}}$ \\
\hline \multirow[t]{4}{*}{$18^{\circ} \mathrm{C}$} & $\mathrm{RE}$ & $50,7 \pm 1,4^{\mathrm{a}}$ & $54,2 \pm 0,8^{a}$ & $50,4 \pm 1,0^{\mathrm{a}}$ & $46,4 \pm 0,6^{\mathrm{a}}$ \\
\hline & $\mathrm{RP}$ & $47,5 \pm 0,9^{\mathrm{a}}$ & $49,1 \pm 0,7^{b}$ & $48,9 \pm 0,9^{\mathrm{a}}$ & $46,3 \pm 1,1^{\mathrm{a}}$ \\
\hline & $\mathrm{CV}(\%)$ & 5,91 & 4,36 & 4,80 & 6,68 \\
\hline & $\mathrm{C}$ & $49,6 \pm 0,6^{\mathrm{a}}$ & $50,2 \pm 0,9^{a}$ & $46,5 \pm 0,8^{a}$ & $45,1 \pm 0,7^{\mathrm{a}}$ \\
\hline \multirow{4}{*}{$25^{\circ} \mathrm{C}$} & $\mathrm{RE}$ & $49,8 \pm 1,6^{\mathrm{a}}$ & $48,6 \pm 1,3^{\mathrm{a}}$ & $47,4 \pm 0,6^{\mathrm{a}}$ & $43,7 \pm 0,8^{a}$ \\
\hline & $\mathrm{RP}$ & $42,2 \pm 0,6^{b}$ & $49,4 \pm 1,2^{\mathrm{a}}$ & $46,2 \pm 0,4^{\mathrm{a}}$ & $42,7 \pm 0,9^{\mathrm{a}}$ \\
\hline & $\mathrm{CV}(\%)$ & 6,20 & 6,52 & 6,58 & 6,11 \\
\hline & $\mathrm{C}$ & $47,9 \pm 0,8^{a b}$ & $49,1 \pm 0,8^{\mathrm{a}}$ & $47,5 \pm 0,7^{\mathrm{a}}$ & $45,1 \pm 0,7^{\mathrm{a}}$ \\
\hline \multirow[t]{5}{*}{$33^{\circ} \mathrm{C}$} & $\mathrm{RE}$ & $48,6 \pm 1,4^{\mathrm{a}}$ & $49,8 \pm 0,8^{a}$ & $48,3 \pm 0,7^{\mathrm{a}}$ & $44,1 \pm 0,9^{\mathrm{a}}$ \\
\hline & $\mathrm{RP}$ & $44,7 \pm 0,9^{b}$ & $47,3 \pm 1,0^{\mathrm{a}}$ & $46,1 \pm 0,6^{\mathrm{a}}$ & $42,5 \pm 1,7^{\mathrm{a}}$ \\
\hline & $\mathrm{CV}(\%)$ & 6,25 & 4,98 & 3,90 & 6,00 \\
\hline & & \multicolumn{4}{|c|}{ Cinzas (\%) } \\
\hline & $\mathrm{C}$ & $8,9 \pm 0,3^{\mathrm{a}}$ & $8,0 \pm 0,3^{\mathrm{a}}$ & $7,9 \pm 0,2^{b}$ & $7,2 \pm 0,3^{\mathrm{a}}$ \\
\hline \multirow[t]{4}{*}{$18^{\circ} \mathrm{C}$} & $\mathrm{RE}$ & $9,0 \pm 0,3^{\mathrm{a}}$ & $8,0 \pm 0,3^{a}$ & $9,1 \pm 0,3^{\mathrm{a}}$ & $7,9 \pm 0,3^{\mathrm{a}}$ \\
\hline & $\mathrm{RP}$ & $8,6 \pm 0,2^{\mathrm{a}}$ & $8,4 \pm 0,4^{\mathrm{a}}$ & $8,1 \pm 0,3^{b}$ & $7,1 \pm 0,2^{\mathrm{a}}$ \\
\hline & $\mathrm{CV}(\%)$ & 8,31 & 10,60 & 9,55 & 10,14 \\
\hline & $\mathrm{C}$ & $8,6 \pm 0,3^{\mathrm{a}}$ & $8,6 \pm 0,5^{\mathrm{a}}$ & $7,1 \pm 0,3^{\mathrm{a}}$ & $7,5 \pm 0,3^{\mathrm{a}}$ \\
\hline \multirow[t]{4}{*}{$25^{\circ} \mathrm{C}$} & $\mathrm{RE}$ & $8,7 \pm 0,2^{\mathrm{a}}$ & $7,6 \pm 0,4^{\mathrm{a}}$ & $8,0 \pm 0,3^{\mathrm{a}}$ & $7,1 \pm 0,4^{\mathrm{a}}$ \\
\hline & $\mathrm{RP}$ & $8,0 \pm 0,3^{\mathrm{a}}$ & $7,6 \pm 0,3^{\mathrm{a}}$ & $7,8 \pm 0,3^{\mathrm{a}}$ & $7,2 \pm 0,3^{\mathrm{a}}$ \\
\hline & $\mathrm{CV}(\%)$ & 9,89 & 13,89 & 11,36 & 13,08 \\
\hline & $\mathrm{C}$ & $8,5 \pm 0,3^{\mathrm{a}}$ & $7,3 \pm 0,3^{\mathrm{a}}$ & $8,2 \pm 0,4^{\mathrm{a}}$ & $6,9 \pm 0,2^{a}$ \\
\hline \multirow[t]{3}{*}{$33^{\circ} \mathrm{C}$} & $\mathrm{RE}$ & $8,3 \pm 0,3^{\mathrm{a}}$ & $7,5 \pm 0,3^{\mathrm{a}}$ & $7,9 \pm 0,2^{\mathrm{a}}$ & $6,8 \pm 0,2^{\mathrm{a}}$ \\
\hline & $\mathrm{RP}$ & $7,8 \pm 0,2^{\mathrm{a}}$ & $7,1 \pm 0,2^{\mathrm{a}}$ & $7,9 \pm 0,4^{\mathrm{a}}$ & $6,5 \pm 0,2^{\mathrm{a}}$ \\
\hline & $\mathrm{CV}(\%)$ & 8,61 & 10,15 & 11,62 & 9,55 \\
\hline \multicolumn{6}{|c|}{$\begin{array}{l}1 \text { Dentro de cada temperatura, médias de uma } \\
2 \text { (Means within a column for each temperature followed } \\
3 \text { Grupo controle (Control group). } \\
4 \text { Restrição energética (Energy restriction). } \\
5 \text { Restrição protéica (Protein restriction). } \\
\text { Coeficiente de variação (Coefficient of variation). }\end{array}$} \\
\hline
\end{tabular}


1064 Rev. bras. zootec.

LILBURN, 1994; SULLIVAN, 1994). Os resultados deste experimento mostraram que a restrição protéica ou energética utilizada na fase inicial de crescimento não foi suficientemente severa para alterar o teor de cinzas total da carcaça das aves.

\section{Conclusões}

Os resultados deste experimento mostraram que, de forma independente da temperatura de criação, as restrições alimentares (energética ou protéica) não afetaram o peso vivo e a composição da carcaça aos 42 dias de idade, evidenciando que o frango em temperaturas ambientes diversas mantém a capacidade de ganho compensatório.

\section{Agradecimento}

À Fundação de Amparo à Pesquisa do Estado de São Paulo (FAPESP), pelo suporte financeiro.

\section{Referências Bibliográficas}

ASSOCIATION OF OFFICIAL ANALYTICAL CHEMISTRY - AOAC. 1975. Official methods of analysis. 12.ed. Washington, D.C. p.1094.

AUCKLAND, J.N., MORRIS, T.R. 1971. Compensatory growth in turkeys: Effect of undernutrition on subsequent protein requirement. Brit. Poult. Sci., 12(1):41-48.

CABEL, M.C., WALDROUP, P.W. 1990. Effect of different nutrient-restriction programs early in life on broiler performance and abdominal fat content. Poult. Sci., 69(4):652-660.

CALVERT, C.C, MCMURTRY, J.P, ROSEBROUGH, R.W. et al. 1987. Effect of energy level on the compensatory growth response of broilers following early feed restriction. Poult. Sci., 66 (Supl.2): 75 (abstract).

DALE, N. 1993. Possible relationship between bone strength and rib breakage: a case study. J. Applied Poult. Res., 2(3):303-306.

FONTANA, E.A., WEAVER JR., W.D., DENBOW, D.M. et al. 1993. Early feed restriction of broilers: Effects on abdominal fat pad, and gizzard weights, fat deposition, and carcass composition. Poult. Sci., 72(2):243-250.

FURLAN, R.L. Efeito da restrição alimentar sobre o crescimento e composição da carcaça de frangos de corte. Jaboticabal, SP: UNESP, 1996. 102 p. Tese (Doutorado em Zootecnia) Universidade Estadual Paulista, 1996.

GIACHETTO, P.F, FERRO, J.A, FERRO, M.I.T. et al. Influência da restrição alimentar e do nível energético da ração sobre o ganho compensatório em frangos de corte. In: REUNIÃO ANUAL DA SOCIEDADE BRASILEIRA DE ZOOTECNIA, 35, 1998, Botucatu. Anais... Botucatu, 1998. p.276-277.

GONZALES, E. Estudo da síndrome de morte súbita em frangos de corte. Jaboticabal, SP: Universidade Estadual Paulista, 1992. 128 p. Tese (Doutorado em Zootecnia) - Faculdade de Ciências Agrárias e Veterinárias, Campus de Jaboticabal, 1992.
JONES, G.P.D., FARREL, D.J. 1992. Early-life food restriction of broiler chickens. II. Effects of food restrictions on the development of fat tissue. Br. Poult. Sci., 33(3):589-601.

LILBURN, M.S. 1994. Skeletal growth of commercial poultry species . Poult. Sci., 73(6):897-903.

MOLLISON, B., GUENTER, W., BOYCOTT, B.R. 1984. Abdominal fat deposition and Sudden Death Syndrome in broilers: The effects of restricted intake, early life caloric (fat) restriction, and calorie: protein ratio. Poult. Sci., 63(6):1190-1200.

MORAN JR, E.T. Nutrição e sua relação com a qualidade de carcaça de frangos de corte. In: CONFERÊNCIA APINCO DE CIÊNCIA E TECNOLOGIA AVÍCOLAS 1992, Santos. Anais ...Santos:FACTA, 1992. p.37-42.

PENZ Jr, A.M. Estresse pelo calor: efeitos em frangos e matrizes manipulação do equilíbrio ácido-base. In: CONFERÊNCIA APINCO DE CIÊNCIA E TECNOLOGIA AVÍCOLAS, 1992, Santos. Anais ... Santos: FACTA, 1992. p.139-145.

PLAVNIK, I., HURWITZ, S. 1985. The performance of broiler chicks during and following a severe feed restriction at an early age. Poult. Sci., 64(2):348-355.

PLAVINIK, I., McMURTRY, J.P., ROSEBROUGH, R.W. 1986. Effect of early feed restriction in broilers. I. Growth performance and carcass composition. Growth, 50(1):68-76.

ROBINSON, F.E., CLASSEN, H.L., HANSON, J.A. et al. 1992. Growth performance, feed efficiency and the incidence of skeletal and metabolic disease in full-fed and feed restricted broiler and roaster chickens. J. Appl. Poult. Res., 1(1):33-41.

ROSEBROUGH, R.W., McMURTRY, J.P. 1993. Energy repletion and lipid metabolism during compensatory gain in broiler chicks. Growth, Develop. and Aging, 57:73-83.

SAS Institute, SAS (Statistical Analisys Sistem). Users guide. SAS institute Inc., Cary, NC. 1998.

SARTORI, J.R., GONZALES, E., SOUZA, E.M. et al. 1997. Efeito do período de jejum na fase final de criação de frangos de corte machos sobre desempenho e mortalidade. R. Bras. Zootec., 26(6):1192-1199.

SARTORI, J.R., GONZALES, E., SOUZA, E.M. et al. 1997 b. Efeito do período de jejum na fase final de criação de frangos de corte machos sobre rendimento e composição da carcaça. R. Bras. Zootec., 26(6):1200-1207.

SULLIVAN, T.W. 1994. Skeletal problems in poultry: estimated annual cost and descriptions. Poult. Sci., 73(6):879-882.

YU, M.W., ROBINSON, F.E., CLANDININ, M.T. et al. 1990. Growth and body composition of broiler chickens in response to different regimens of feed restriction. Poult. Sci., 69(12):2074-2081.

WALDROUP, P.W., MITCHELL, R.J., PAYNE, J.R. et al. 1976. Performance of chicks fed diets formulated to minimize excess levels of essential amino acids. Poult. Sci., 55(1):243-253.

ZUBAIR, A.K., LEESON, S. 1994. Effect of varying period of early nutrient restriction on growth compensation and carcass characteristics of male broilers. Poult. Sci., 73(1):129-136.

ZUBAIR, A.K., LEESON, S. 1996. Compensatory growth in the broiler chicken: a review. World's Poult. Sci. J., 52(2):189-201.

Recebido em: 24/03/00 Aceito em: 15/01/01 